\title{
Conhecimento de estudantes da saúde sobre suporte básico de vida
}

\author{
Basic life support knowledge of healthcare students \\ Conocimiento del estudiante de salud sobre el apoyo básico de la vida
}

Laisla Fernandes de Nogueira Rosa ${ }^{1}$, Jheinny Mayara Caimi ${ }^{2}$, Lívia Pacheco

Gonçalves $^{3}$, Mariana Xavier e Silva ${ }^{4}$

\begin{abstract}
${ }^{1}$ Médica pela Faculdades Pequeno Príncipe. Curitiba, Paraná
${ }^{2}$ Médica pela Faculdades Pequeno Príncipe. Curitiba, Paraná

${ }^{3}$ Médica pela Faculdades Pequeno Príncipe. Curitiba, Paraná

${ }^{4}$ Mestre em Medicina pela Pontifícia Universidade Católica do Paraná. Vice-coordenadora do Internato do Curso de Graduação em Medicina da Faculdades Pequeno Príncipe. Curitiba, Paraná
\end{abstract}

\section{RESUMO}

O objetivo deste artigo é identificar o conhecimento dos estudantes da área da saúde sobre Suporte Básico de Vida. Este é um estudo transversal com abordagem quantitativa. Foi feita a aplicação de um questionário para discentes da área da saúde de todos os cursos e períodos vigentes na instituição selecionada. O questionário foi submetido para 545 estudantes e avaliou três domínios em 25 perguntas: conhecimentos gerais, sequência dos procedimentos e método de aplicação dos procedimentos. Nossos resultados demonstraram que 28,1\% dos entrevistados sabiam a sequência de atendimento do SBV, sobre o acionamento do serviço de emergência 30,3\% o fariam no momento adequado e sobre a o uso do DEA 18,9\% sabiam utilizar o aparelho. Esse

Autor de Correspondência:

*Laisla Fernandes de Nogueira Rosa. E-mail: laislarosa@hotmail.com 
estudo demonstra algumas deficiências dos entrevistados sobre SBV, reforçando a necessidade do ensino continuado em SBV e a importância do incentivo a iniciativas de divulgação do tema.

Palavras-chave: Reanimação Cardiopulmonar. Estudantes de Ciências da Saúde. Emergências.

\begin{abstract}
The objective of this article is to identify basic life support knowledge of healthcare students of a higher education institution through the application of a questionnaire for students of the health area of all courses and current terms in the selected institution. This is a crosssectional study with a quantitative approach. The questionnaire was applied to 545 students and evaluated three domains in 25 questions: general knowledge, sequence of procedures, and the method of use of procedures. Our analysis showed that $28.1 \%$ of the interviewed knew the Basic Life Support sequence, $30.3 \%$ would call the emergency service timely, and $18.9 \%$ knew how to use the Automated External Defibrillator. This study shows some deficient knowledge on basic life support of the students interviewed, reinforcing the need for its continuous teaching and the importance of encouraging initiatives to disseminate the theme.
\end{abstract}

Keywords: Cardiopulmonary Resuscitation. Students, Health Occupations. Emergencies

\title{
RESUMEN
}

El propósito de este artículo es resaltar el conocimiento de los estudiantes de una institución de educación superior sobre SVB mediante la aplicación de un cuestionario para alumnos de todas las especialidades del área de la salud de todos los cursos y períodos vigentes. Este es un estudio transversal con un enfoque cuantitativo. El cuestionario se aplicó a 545 estudiantes y evaluó tres dominios en 25 preguntas: conocimiento general, secuencia de procedimientos y método de aplicación de los procedimientos. Nuestros resultados mostraron que el 28.1\% de los entrevistados conocía la secuencia del servicio BLS, sobre la activación del servicio de emergencia, el 30.3\% lo haría en el momento adecuado y sobre el uso de la DEA, el 18.9\% sabía cómo usar el dispositivo. Este estudio refuerza la necesidad de la enseñanza del SVB y la importancia de iniciativas para difusión del tema.

Palabras clave: Reanimación Cardiopulmonar. Estudiantes del Área de la Salud. Urgencias Médicas 


\section{INTRODUÇÃO}

A parada cardiorrespiratória (PCR) é uma complicação de um evento clínico ou traumático causadora de morbidade e mortalidade na população adulta e pediátrica. A incidência de paradas cardíacas fora de hospitais varia de 20 a 140 para 100.000 pessoas e a sobrevivência é de aproximadamente $2 \%$ a $11 \%$. A chance de recuperação integral diminui exponencialmente com a demora no atendimento inicial. Quando uma PCR ocorre em ambiente extra-hospitalar a chance de sobrevida fica muito comprometida ${ }^{1}$.

Para o atendimento dessa emergência, com o conhecimento em suporte básico de vida, é possível identificar precocemente e realizar manobras simples de ressuscitação cardiopulmonar salvando vidas. Esse procedimento pode ser praticado por qualquer pessoa independente de sua formação técnica ${ }^{2}$.

Para um atendimento satisfatório é necessário, primeiramente, reconhecer os sinais de uma PCR. Segundo a AHA (American Heart Association) ao encontrar um paciente não responsivo, sem respiração ou com respiração anormal deve-se procurar por ajuda, acionar o serviço de emergência e começar imediatamente as compressões torácicas ${ }^{3}$.

O número de compressões torácicas aplicadas por minuto durante a RCP é um fator essencial para o retorno da circulação espontânea (RCE) e da sobrevivência com boa função neurológica. Uma frequência de compressão inadequada e/ou interrupções frequentes reduzirão o número total de compressões aplicadas por minuto, piorando o prognóstico do paciente ${ }^{4}$.

Desta maneira, é importante que a RCP seja de alta qualidade. Esta inclui: frequência de compressão mínima de 100-120/minuto, profundidade de compressão mínima de 2 polegadas $(5 \mathrm{~cm})$, em adultos e crianças, e em bebês $4 \mathrm{~cm}$, retorno total do tórax após cada compressão, minimização das interrupções nas compressões torácicas e evitar excesso de ventilação. Uma RCP de alta qualidade eleva os níveis de sobrevivência dos pacientes. Outro detalhe importante é que as últimas diretrizes nos trazem o protocolo "hands-only CPR", no qual o manejo do paciente em parada cardiorrespiratória no SBV pode ser feito apenas através das compressões torácicas, sem manobras de respiração ${ }^{5}$.

A chance de recuperação integral após uma PCR diminui exponencialmente com a demora no atendimento inicial. O ideal seria que toda a população estivesse apta a realizar um primeiro atendimento e não somente profissionais da área da saúde. Mas, deste último grupo espera-se que o conhecimento sobre o SBV seja bom e eficaz ${ }^{6}$.

É, portanto, relevante avaliar o conhecimento dos estudantes da área da saúde sobre SBV, uma vez que esses estudantes além de estarem aptos a realizar um primeiro atendimento, ainda são considerados disseminadores de conhecimento ${ }^{4}$.

Em 2010, as diretrizes RCP e de atendimento para esse tipo de emergência foram modificadas pela American Heart Association, e em 2015 foi mantida essa alteração. Antes o protocolo de atendimento era A-B-C (via aérea, respiração, compressões torácicas) e agora o atendimento passou a ser C-A-B (compressões torácicas, via aérea, respiração) em adultos, crianças e bebês. A justificativa se dá pelo fato de as compressões torácicas manterem o fluxo sanguíneo e oxigenação do coração e cérebro. As compressões torácicas podem ser iniciadas quase imediatamente, ao passo que a via aérea em algumas situações tem difícil abordagem ${ }^{7}$.

As PCRs ocorrem por motivos diferentes em adultos e crianças. A maioria das PCRs em adultos, na qual a PCR foi detectada com ritmo inicial de fibrilação ventricular (FV) ou taquicardia ventricular (TV) sem pulso. Nesses pacientes, os elementos iniciais críticos de SBV (suporte básico de vida) são compressões torácicas e a desfibrilação precoce ${ }^{8}$. 
No entanto, é muito pequena a parcela da população que de fato sabe como prestar um primeiro atendimento, seja ela leiga ou não. Estudos evidenciam que apesar de $90 \%$ dos profissionais de saúde, quando questionados, declararem serem aptos a efetuar esse primeiro atendimento ao serem avaliados, menos de $40 \%$ dos participantes conseguiram realizar as manobras corretamente ${ }^{9}$.

Desta forma, tratando-se de PCR, o atendimento não adequado, demorado, de baixa qualidade, impacta demasiadamente a taxa de sobrevivência livre de sequelas e evidencia a necessidade de educação continuada, seja de crianças ou de estudantes da área de saúde em suporte básico de vida ${ }^{10}$.

Todos esses dados reforçam a necessidade de disseminar os conhecimentos sobre SBV para toda a população e no futuro as fatalidades desse tipo de ocorrência sejam as menores possíveis decorrentes de um atendimento demorado ou inadequado. Para tanto, é necessário que os estudantes da área da saúde estejam aptos para atender e disseminar seu conhecimento para toda a população ${ }^{11}$.

Estudantes da área da saúde devem, além de ser aptos a realizar o atendimento dentro do SBV, difundir esses conceitos, seja em seu círculo de convívio ou até mesmo através das redes sociais, pois sempre há uma dúvida entre pessoas leigas e são os estudantes que são buscados por ajuda, além de que quando se ensina há uma reafirmação do conhecimento ${ }^{12}$.

Diante da contextualização sobre o tema, esta pesquisa propõe-se identificar o conhecimento de estudantes da área de saúde em instituição de ensino superior de Curitiba, sobre suporte básico de vida.

\section{MÉTODO}

Este é um estudo do tipo transversal com abordagem quantitativa. O estudo foi realizado em instituição de ensino superior de Curitiba.

O projeto foi submetido ao Comitê de Ética em Pesquisa (CEP) da instituição no mês de junho de
2017 e segue os preceitos éticos de acordo com a resolução 466/12, sob o parecer n ${ }^{\circ}$ 2.419.090 .

Os participantes foram entrevistados nos períodos diurnos e noturnos nas instalações da faculdade, no período entre as aulas, nas salas de aulas, sendo respondido e entregue aos autores no mesmo momento. O questionário foi aplicado no período de dezembro de 2017 a abril de 2018.

Os participantes foram os discentes da área da saúde de todos os cursos e períodos vigentes da instituição de ensino superior: biomedicina, enfermagem, farmácia, medicina e psicologia. Somente participaram aqueles que tinham disponibilidade e interesse em responder aos questionários e que assinaram o termo de consentimento livre e esclarecido (TCLE).

O instrumento de coleta utilizado foi um questionário de 25 perguntas de múltipla escolha, sendo que cada pergunta apresentava 4 possíveis respostas, das quais somente uma era a correta. ${ }^{13}$

O questionário avaliou os seguintes domínios: conhecimentos gerais (7 perguntas), sequência dos procedimentos (7 perguntas); método de aplicação dos procedimentos (11 perguntas). Já a última seção foi subdividida em 4 perguntas referentes à ventilação, 3 referentes à compressão torácica e 4 referentes ao uso de um Desfibrilador Externo Automático (DEA).

Os dados foram coletados e armazenados em uma planilha do Microsoft Excel ${ }^{\circledR}$. A análise de dados foi realizada com o auxílio do programa computacional SPSS v.22.0. Os resultados foram expressos por médias, medianas, valores mínimos, valores máximos e desvios padrões (variáveis quantitativas) ou por frequências e percentuais (variáveis qualitativas). A análise inferencial foi realizada por meio de Testes estatísticos Qui Quadrado de Pearson, Teste Exato de Fisher, Teste T de Student e o teste ANOVA. Os valores de $\mathrm{p}$ menores que 0,05 são considerados significativos. 


\section{RESULTADOS}

A amostra foi constituída por 545 participantes da pesquisa, com idade média de $22 \pm 5$ anos. Os entrevistados pertenciam a diferentes cursos em ciências da saúde, como biomedicina, enfermagem, farmácia, medicina e psicologia, escolhidos aleatoriamente, conforme disponibilidade e interesse em responder ao questionário (Tabela 1).

Tabela 1 - Caracterização da população de estudantes de graduação em Ciências da Saúde, Curitiba, Brasil, 2018.

\begin{tabular}{lcc}
\hline \multicolumn{1}{c}{ VARIÁVEIS CONSIDERADAS } & N & \% \\
\hline Sexo & & \\
\hline Feminino & 430 & 78,9 \\
\hline Masculino & 115 & 21,1 \\
\hline Média dos acertos gerais & 14,1 & 56,4 \\
\hline Curso & & \\
\hline Biomedicina/Farmácia & 123 & 22,6 \\
\hline Enfermagem & 50 & 9,2 \\
\hline Medicina & 228 & 41,8 \\
\hline Psicologia & 144 & 26,4 \\
\hline Período & & \\
\hline 1 & 93 & 17,1 \\
\hline 2 & 59 & 10,8 \\
\hline 3 & 74 & 13,6 \\
\hline 4 & 64 & 11,7 \\
\hline 5 & 46 & 8,4 \\
\hline 6 & 71 & 13 \\
\hline 7 & 45 & 8,3 \\
\hline 8 & 50 & 9,2 \\
\hline 9 & 43 & 7,9 \\
\hline Treinamento prévio & & \\
\hline Sim & 287 & 52,7 \\
\hline Não & 258 & 47,3 \\
\hline
\end{tabular}

Do total de participantes da pesquisa entrevistado prevaleceu o sexo feminino 430 (78,9\%), estar cursando Medicina 228 (41,8\%), ser do primeiro período $93(17,1 \%)$ e que já participaram previamente de um treinamento sobre RCP 287 (52,7\%).
$\mathrm{Na}$ análise do questionário em estudo o qual continha 25 questões, a média de acertos foi de 14 questões (56,41\%). O número mínimo de acertos foi de 4 questões e o máximo foi de 25 questões. (Gráfico 1) 
Gráfico 1 - Percentual de acertos dos participantes por questão.

\section{Percentual de acertos}

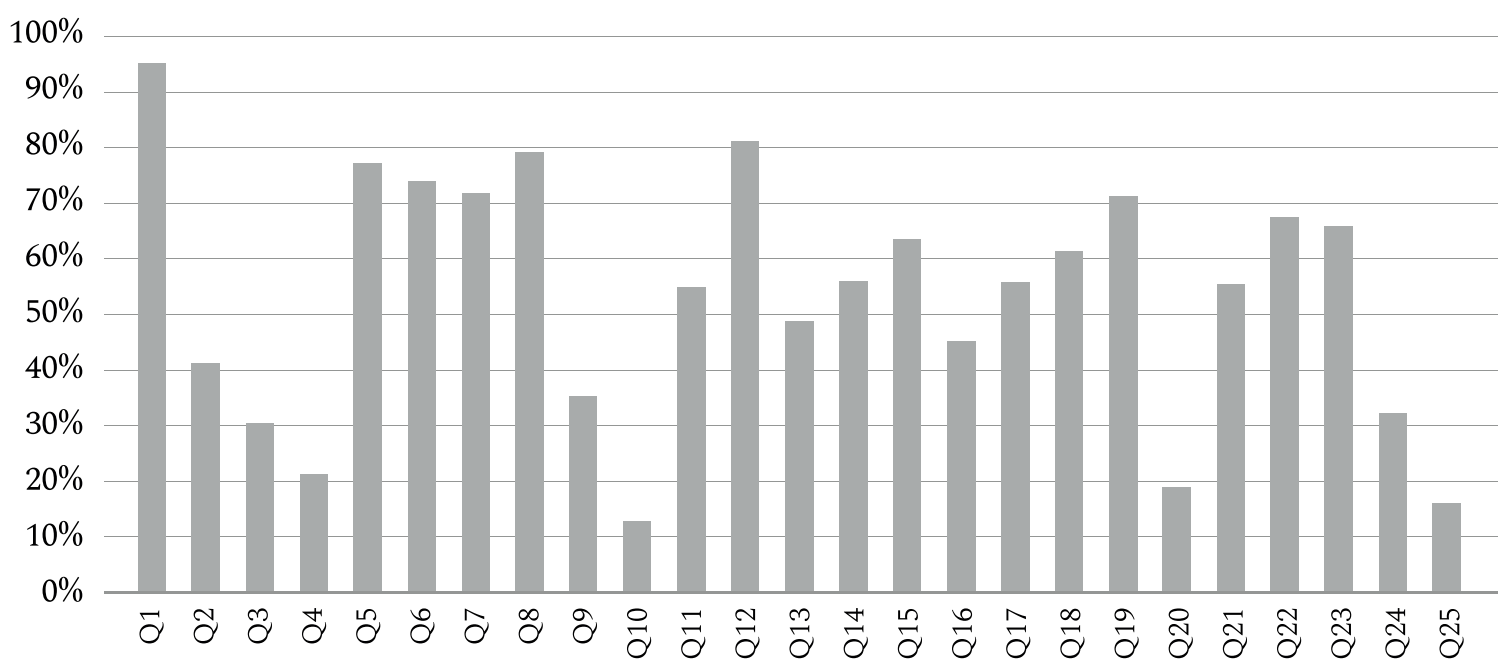

Número da questão

Quando questionados sobre a sequência de atendimento, $153(28,1 \%)$ responderam corretamente: "verificar se a vítima responde ao ser chamada". $\mathrm{Na}$ sequência do atendimento, que seria acionar o serviço de emergência, 30,3\% marcaram a alternativa correta e, por fim, apenas $16,9 \%$ verificaram a respiração nesta etapa. Quanto à realização da manobra para facilitar a respiração 69 (12,7\%) responderam corretamente. Ainda sobre o tópico respiração, a opção de aplicar respirações boca a boca foi considerada por 179 $(32,8 \%)$ dos participantes da pesquisa.

Durante o estudo, 420 (77,1\%) dos participantes acertaram o número de telefone do serviço de emergência. Ainda sobre a busca ao serviço de emergência, 403 (73,9\%) dos acadêmicos manteriam a chamada com a central enquanto fariam o atendimento, enquanto $142(26,1 \%)$ informariam ao serviço sobre o ocorrido e finalizariam a chamada.

Sobre as compressões torácicas e a verificação do pulso da vítima, $298(54,7 \%)$ responderam que é preciso verificar o pulso na região da artéria carótida, $304(55,8 \%)$ assumiram que correto é a realizar 30 compressões entre cada ventilação e 265 (48,6\%) sabiam que compressões precisam ser feitas com força e rapidamente.

Sobre o uso do DEA 103 (18,9\%) dos participantes marcaram a alternativa correta: como colocar as pás, ligar o aparelho e proceder após sua utilização e 87 (16\%) dos entrevistados sabiam como proceder quando a ajuda chegasse.

$\mathrm{Na}$ análise comparativa dos resultados obtevese 2 grandes grupos. O grupo 1 correspondente a estudantes do $1^{\circ}$ ao $4^{\circ}$ período de todos os cursos totalizando 290 (53,21\%), e o grupo 2 representando os graduandos do $5^{\circ}$ ao $9^{\circ}$ período 255 (46,78\%). No primeiro grupo, a média de acertos foi de 13,08 questões, já no segundo a média foi de 15,27. 
Outro tópico analisado foi o número de acertos de questões por período. A média de acertos do primeiro período foi de 11,12 questões e dos últimos períodos, a média foi de 16,4 questões (Tabela 2).

Tabela 2 - Média de acertos de questões por período

\begin{tabular}{|c|c|c|}
\hline Período & $\begin{array}{l}\text { Número de } \\
\text { alunos }\end{array}$ & $\begin{array}{l}\text { Média de } \\
\text { acertos }\end{array}$ \\
\hline $1^{\circ}$ & 93 & 11,12 \\
\hline $2^{\underline{o}}$ & 59 & 13,9 \\
\hline $3^{\circ}$ & 74 & 13,7 \\
\hline $4^{\circ}$ & 64 & 14,44 \\
\hline $5^{\circ}$ & 46 & 15,37 \\
\hline $6^{\circ}$ & 71 & 15,39 \\
\hline $7^{\circ}$ & 45 & 16 \\
\hline $8^{\circ}$ & 50 & 16,46 \\
\hline $9^{\circ}$ & 43 & 12,81 \\
\hline Total & 545 & 14,1 \\
\hline
\end{tabular}

Fonte: Dados da pesquisa

\section{DISCUSSÃO}

As etapas do SBV compreendem o reconhecimento da parada, as manobras de reanimação e o acesso rápido ao suporte avançado de vida. $\mathrm{Na}$ abordagem inicial do paciente deve-se observar o nível de consciência e a respiração da vítima, que pode ser feito simplesmente chamando a vítima e analisando se há resposta efetiva. Neste estudo, $28,1 \%$ responderam corretamente qual seria o primeiro passo ao encontrar alguém inconsciente no chão. Contudo, quase a metade dos candidatos responderam que o ideal seria verificar se a vítima está respirando primeiro, esse fato pode comprometer a qualidade do socorro prestado ${ }^{14}$.

O tempo entre o evento e o início da assistência constitui um fator importante durante o atendimento de uma pessoa inconsciente. A análise das respostas sobre qual o serviço de emergência deve ser procurado, demonstrou que apesar da maioria, $420(77,1 \%)$, ter respondido SAMU (192), para uma parcela dos participantes, 99 (18,2\%), o serviço a ser procurado nestes casos é o SIATE (193), a forma como os serviços de urgência e emergência atuam mudam de cidade e região do País e esses dados refletem a dificuldade em diferenciar os serviços de emergência entre alunos do ensino superior, sendo essa diferença ainda maior na população leiga, segundo levantamentos do SAMU e do SIATE ${ }^{6}$.

Depois de pedir ajuda, é essencial avaliar a respiração da vítima. Dentre os entrevistados, $79,1 \%$ dos participantes sabiam verificar a presença de movimentos respiratórios, mas acima de $70 \%$ não sabiam realizar manobras para facilitar a respiração e apenas 32\% realizariam respiração boca a boca. A avaliação e manejo da via aérea é de extrema dificuldade para pessoas não treinadas e é um fator de atraso à desfibrilação precoce ${ }^{15}$.

Ainda sobre a respiração e ventilação a AHA preconiza para socorristas e pessoas treinadas, na realização da RCP usando compressões torácicas e ventilação (ventilação de resgate), é plausível aplicar ventilação entre as compressões para RCP extra-hospitalar em adultos. Neste estudo, a opção aplicar respirações boca a boca foi considerada por $179(32,8 \%)$ dos participantes da pesquisa. Realizar respiração boca a boca é muito discutido, pois sem dispositivos de proteção individual adequado, a chance de contaminação da equipe com outras doenças infectocontagiosas é alta ${ }^{16}$.

As novas atualizações da AHA em 2017 afirmam que aqueles que foram treinados e desejarem realizar ventilação (boca a boca) não devem ser proibidos de fazê-lo. Porém o próprio órgão (AHA) também publicou que aqueles não treinados deveriam somente realizar as compressões torácicas, uma vez que fazendo uma ventilação equivocada haveria prejuízo ao paciente. Isso ocorre primeiramente, 
porque enquanto realizavam a ventilação paravam as compressões e, segundo, porque ventilações equivocadas podem causar insuflações gástricas, aumentando a chance de broncoaspiração. Esses dados explicam a baixa porcentagem de estudantes que aplicariam ventilação boca a boca ${ }^{7}$.

A parada cardiorrespiratória (PCR) em si é a cessação da circulação e da respiração. Em um atendimento a uma vítima de PCR, as compressões torácicas são de vital importância. Durante a análise das respostas sobre o número de compressões entre as ventilações, notou-se discordância entre os acadêmicos, visto que $304(55,8 \%)$ realizariam 30 compressões entre cada ventilação e $123(22,6 \%)$ realizariam 15 compressões, um possível reflexo das mudanças de protocolos entre o atendimento adulto e pediátrico. Sendo que atualmente é preconizado o padrão 30:2 para todas as faixas etárias no atendimento realizado por somente uma pessoa ${ }^{17}$.

Durante a caracterização dessas compressões, menos da metade assinalaram a alternativa que trazia que essas compressões deviam ser com força e rapidamente, sendo que a maneira como é feita as compressões é um impactante direto da taxa de mortalidade e complicações posteriores. As compressões devem ser feitas com força e rapidamente, em uma frequência de no mínimo 100 compressões por minuto e aplicando uma força para deprimir o esterno em $5 \mathrm{~cm}$. Deve-se também ater-se ao fato de que entre cada compressão é necessário permitir o retorno completo do tórax para que a circulação proporcionada pela RCP seja capaz de circular pelo corpo ${ }^{14}$

Quando o serviço de emergência chega no local, o DEA deve ser imediatamente instalado, visto que, se o ritmo de parada da vítima for chocável, ele pode ser revertido rapidamente. O DEA pode ser facilmente usado por pessoas leigas, por serem totalmente automáticos, e após serem ligados e conectados ao paciente não exigem mais a interferência humana ${ }^{18}$.

Neste estudo, $18,90 \%$ dos participantes sabiam que o primeiro passo para utilização do DEA é ligar o aparelho e $16 \%$ sabiam o que fazer após o choque. Por se tratar de um aparelho de uso e acesso fácil, deve estar presente em lugares com grande fluxo de pessoas, é muito impactante perceber essa dificuldade. Há uma falta de conhecimento envolvido que traz medos e dúvidas, e isso só traz consequências maléficas ao paciente. Diante de situações como essas, a conduta a se tomar é permanecer calmo, chamar ajuda e ligar o aparelho, ele trará as instruções do que deverá ser feito $^{19}$.

Um ponto relevante a ser discutido é que mesmo estando nos períodos finais da graduação com o foco para a prática clínica, houve uma dificuldade em responder questões essenciais do questionário. Evidenciando a necessidade de retomar conceitos estudados nos primeiros períodos com o suporte básico de vida ${ }^{18,20}$.

\section{CONCLUSÕES}

Os resultados deste estudo identificaram que os estudantes da área da saúde possuem alguns déficits sobre SBV visto que uma parcela significativa de acadêmicos não respondeu de maneira adequada os tópicos abordados retirados do SBV e não conhecia a fundamentação das etapas deste, de acordo com as novas atualizações da AHA o que pode, de fato, comprometer o atendimento prestado. Dessa maneira, este estudo reforça a necessidade do ensino em SBV aos estudantes da área da saúde.

O ensino de habilidades durante a graduação corrobora de maneira positiva na formação desses acadêmicos, uma vez que são realizadas discussões sobre o assunto e inúmeros treinamentos, tornando este estudante apto a prestar os primeiros socorros. Outro ponto positivo no implemento da cadeira de habilidades é que esses alunos se tornam mais confiantes no atendimento inicial, além de disseminadores de conhecimento e formadores 
de opinião, podendo contribuir com o ensino dos primeiros socorros a toda a sociedade.

Apesar de ser um questionário validado e publicado em revista de interesse, o mesmo apresenta limitações, como nas primeiras perguntas em que traz a sequência de atendimento do SBV. Se não for percebido que esse era o objetivo das questões, o erro de 1 questão comprometerá a resposta das outras, devendo ser lido e respondido com calma. Outra limitação é que diante das constantes atualizações no assunto, os participantes podem responder incorretamente dependendo da referência que o mesmo aprendeu o assunto.

Por fim, é fundamental que as instituições de ensino superior incentivem rotineiramente iniciativas de divulgação do SBV, como seminários, congressos, ligas acadêmicas, palestras e projetos de extensão, para que todos estejam aptos a realizar um primeiro atendimento de qualidade e, dessa forma, salvar vidas.

\section{REFERÊNCIAS}

1. Kleinman ME, Brennan EE, Goldberger ZD, Swor RA, Terry M, Bobrow BJ, Gazmuri RJ, Travers AH, Rea T. Part 5: adult basic life support and cardiopulmonary resuscitation quality: 2015 American Heart Association guidelines update for cardiopulmonary resuscitation and emergency cardiovascular care. Circulation. 2015; 132(suppl 2):S414S435. doi: 10.1161/CIR.0000000000000259.

2. Pergola AM, Araujo IEM. O leigo e o suporte básico de vida TT - El lego y el soporte básico de vida TT Laypeople and basic life support. Rev da Esc Enferm da USP [Internet]. 2009;43(2):335-42. Available at: http:// www.scielo.br/scielo.php?script=sci_arttext\&pid=S008062342009000200012\&lang=pt\%0Ahttp://www.scielo.br/pdf/ reeusp/v43n2/a12v43n2.pdf\%0Ahttp://www.scielo.br/pdf/ reeusp/v43n2/en_a12v43n2.pdf

3. Fran M, Michael H, Samson RA, Schexnayder SM, Travers AH, Barnes D, et al. 2015 American Heart Association Guidelines Update for. 2015;2015.
4. Quilici, Ana Paula - Timerman S. Suporte Básico de Vida - Primeiro Atendimento Na Emergência Para Profissionais da Saúde. Manole. Brasil; 2011. 376 p.

5. Soar J, Nolan JP, Böttiger BW, Perkins GD, Lott C, Carli P, et al. European Resuscitation Council Guidelines for Resuscitation 2015. Section 3. Adult advanced life support. Resuscitation. 2015;95:100-47

6. Pergola AM, Araujo IEM. O leigo em situação de emergência. Rev da Esc Enferm da USP. 2008;42(4):769-76.

7. D e s ta qu e s. Am Hear Assoc. 2015;

8. Craig-brangan BYKJ, Day MP. Update : 2017 / 2018 AHA BLS , ACLS , and PALS guidelines. 2019;49(2):2017-20.

9. Tavares LFB, Bezerra IMP, Oliveira FR, Sousa LV de A, Raimundo RD, de Sousa EC, et al. Knowledge of health sciences undergraduate students in objective tests on basic life support. J Hum Growth Dev. 2015;25(3):297-306.

10. Greif R, Lockey AS, Conaghan P, Lippert A, De Vries W, Monsieurs KG, et al. European Resuscitation Council Guidelines for Resuscitation 2015. Section 10. Education and implementation of resuscitation. Resuscitation. 2015;95:288-301.

11. Ribeiro LG, Germano R, Menezes PL, Schmidt A, PazinFilho A. Estudantes de medicina ensinam ressuscitação cardiopulmonar a alunos do fundamental. Arq Bras Cardiol. 2013;101(4):328-35.

12. Silva DR da, Lima LR de A e, Cara LM, Wen CL. Projeto Jovem Doutor: o aprendizado prático de estudantes de medicina por meio de atividade socioeducativa TT - Young Doctor Project-Health in Schools: potential learning of medical students through taking part in socio-educational activity. Rev med (Säo Paulo) [Internet]. 2017;96(2):73-80. Available at: https://www.revistas.usp.br/revistadc/article/ view/119445/129427

13. Ribeiro LG, Germano R, Menezes PL, Schmidt A, PazinFilho A. Estudantes de medicina ensinam ressuscitação cardiopulmonar a alunos do fundamental. Arq Bras Cardiol. 2013;101(4):328-35.

14. Perkins GD, Handley AJ, Koster RW, Castrén M, Smyth MA, Olasveengen T, et al. European Resuscitation Council Guidelines for Resuscitation 2015. Section 2. Adult basic life support and automated external defibrillation. Resuscitation. 2015;95:81-99 
15. Castan C, Münch A, Mahling M, Haffner L, Griewatz J, Hermann-Werner A, et al. Factors associated with delayed defibrillation in cardiopulmonary resuscitation: A prospective simulation study. PLoS One. 2017;12(6):1-11.

16. Association AH. Atualizações Específicas das Diretrizes de 2017. 2017;

17. Haluka J, Liu LA. BLS Pediatric Algorithm, 2020.

18. Morais DA, Carvalho DV, Correa A dos R. Out-ofhospital cardiac arrest: Determinant factors for immediate survival after cardiopulmonary resuscitation. Rev Lat Am Enfermagem. 2014;22(4):562-8.

19. de Vries W, Handley AJ. A web-based micro-simulation program for self-learning BLS skills and the use of an AED. Can laypeople train themselves without a manikin? Resuscitation. 2007;75(3):491-8.

20. Le D, Le B, Golub J, Kri M, Mally Š, Grmec Š. Impact of additional module training on the level of basic life support knowledge of first year students at the University of Maribor. 2011;1-8. 